Published in final edited form as:

J Am Chem Soc. 2019 September 25; 141(38): 15367-15377. doi:10.1021/jacs.9b07885.

\title{
Catalytic Enantioselective Synthesis of Cyclobutenes from Alkynes and Alkenyl Derivatives
}

\author{
Mahesh M. Parsutkar, Vinayak Vishnu Pagar, T. V. RajanBabu* \\ Department of Chemistry and Biochemistry, The Ohio State University, 100 West 18th Avenue, \\ Columbus, OHIO 43210, USA
}

\section{Abstract}

Discovery of enantioselective catalytic reactions for the preparation of chiral compounds from readily available precursors, using scalable and environmentally benign chemistry, can greatly impact their design, synthesis and eventually manufacture on scale. Functionalized cyclobutanes and cyclobutenes are important structural motifs seen in many bioactive natural products and pharmaceutically relevant small molecules. They are also useful precursors for other classes of organic compounds such as other cycloalkane derivatives, heterocyclic compounds, stereo-defined 1,3-dienes and ligands for catalytic asymmetric synthesis. The simplest approach to make cyclobutenes is through an enantioselective [2+2]-cycloaddition between an alkyne and an alkenyl derivative, a reaction which has a long history. Yet known reactions of this class that give acceptable enantioselectivities are of very narrow scope and are strictly limited to activated alkynes and highly reactive alkenes. Here we disclose a broadly applicable enantioselective [2+2]cycloaddition between wide variety of alkynes and alkenyl derivatives, two of the most abundant classes of organic precursors. The key cycloaddition reaction employs catalysts derived from readily synthesized ligands and an earthabundant metal, cobalt. Over 50 different cyclobutenes with enantioselectivities in the range of $86-97 \%$ ee are documented. With the diverse functional groups present in these compounds, further diastereoselective transformations are easily envisaged for synthesis of highly functionalized cyclobutanes and cyclobutenes. Some of the novel observations made during these studies including a key role of a cationic Co(I)-intermediate, ligand and counter ion effects on the reactions, can be expected to have broad implications in homogeneous catalysis beyond the highly valuable synthetic intermediates that are accessible by this route.

\section{Graphical Abstract}

\footnotetext{
*Corresponding Author rajanbabu.1@ osu.edu. The authors declare no competing financial interest. ASSOCIATED CONTENT Supporting information

This Information is available free of charge via the Internet at http://pubs.acs.org. Experimental procedures, syntheses and isolation of all intermediates, and Tables with details of several optimization studies. Spectroscopic and chromatographic data showing compositions of products under various reaction conditions (PDF).

Crystallographic Information for complex $[(R)-\mathbf{L 8}] \mathrm{CoBr}_{2}(\mathrm{CIF})$ Crystallographic Information for (S)-9-1,6-dibromo-2-naphthoate ester (CIF). Data have been deposited at the Cambridge Crystallographic Data Centre under accession numbers CCDC 1860755 and 1921037 respectively.
} 

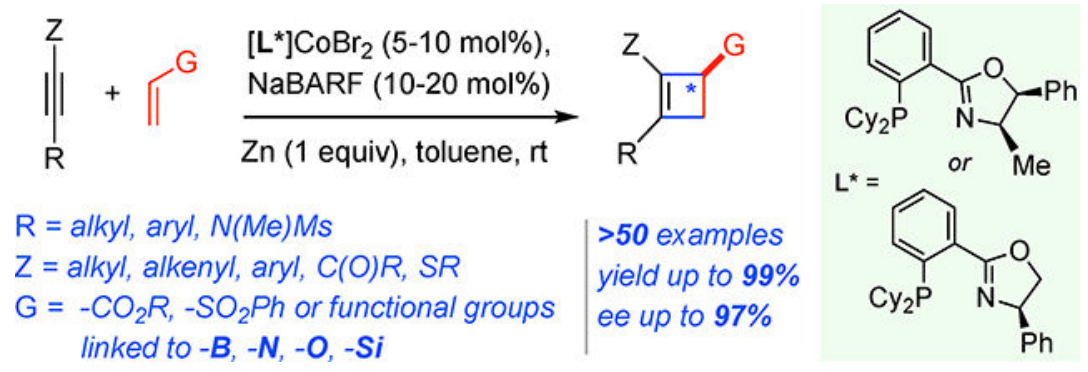

\section{INTRODUCTION}

Recent incisive analyses of reactions ${ }^{1}$ and molecules ${ }^{2}$ of interest to medicinal chemists have validated the notion that molecular complexity, measured by fraction of saturated carbons (Fsp3) and the presence of chiral centers, correlate with success as compounds move from discovery, through clinical testing, to drugs. About a third of the compounds whose biological assays were analyzed had at least one chiral center. ${ }^{1}$ The improved clinical efficacy has been ascribed to solubility, diminished promiscuity towards receptors, and occasionally, to better transport properties across biological barriers. Practical considerations in the preparation and screening of large and diverse array of structures, and, eventually manufacturing of the successful candidates from readily available precursors, provide strong justification for research into efficient and enantioselective synthetic methods. ${ }^{3}$

Functionalized cyclobutanes and cyclobutenes are important structural motifs seen in many bioactive natural products and pharmaceutically relevant small molecules (Figure 1, A). ${ }^{4}$ They are also useful precursors for other classes of organic compounds such as other cycloalkane derivatives, heterocyclic compounds, stereo-defined 1,3-dienes and ligands for catalytic asymmetric synthesis. ${ }^{5}$ Even though direct synthesis of suitably functionalized cyclobutane precursors from readily available starting materials has been the subject of a burgeoning area of research, ${ }^{6}$ there is considerable room for improvement with respect to diversity of functional groups on the ring and stereoselectivity associated with the ring formation. In this regard, a class of compounds with enormous potential for diversification are the chiral 3-substituted cyclobutenes (Figure 1, B), which allow further modification of the small ring through a myriad of ways involving the double bond, ${ }^{7}$ the G group ${ }^{8}$ or through activation of the ring C-H bonds. ${ }^{9}$ The simplest approach to making cyclobutenes is through an enantioselective [2+2]- cycloaddition between an alkyne and an alkenyl derivative, a reaction with a long history, starting with mostly addition of reactive alkynes to bicyclic $^{10}$ or activated ${ }^{11}$ alkenes with the notable exceptions of additions of activated alkynes to cyclopentene (Hilt) ${ }^{12 \mathrm{a}}$ and a variety of styreneyl alkenes to enynes (Ogoshi), ${ }^{12 \mathrm{~b}}$ both giving racemic products. Thus, there are no examples in the literature of a broadly applicable enantioselective version of this [2+2]-cycloaddition process. Reactions that give acceptable enantioselectivities are limited to specialized substrates, most often strained alkenes or activated alkynes (example: Figure $1, \mathrm{C}$ ). ${ }^{13}$ Here we disclose a broadly applicable enantioselective [2+2]-cycloaddition between wide spectrum of alkenyl derivatives and alkynes (Figure 1, D). 


\section{RESULTS AND DISCUSSION}

For the enantiopure, substituted cyclobutenes (Figure 1, B) as the targets, we recognized that none of the existing methods ${ }^{11 \mathrm{c} .11 \mathrm{e}-\mathrm{g} .13 \mathrm{a}}$ including our own recently disclosed ${ }^{7 \mathrm{a}}$ enantioselective cobalt-catalyzed cycloaddition between an enyne (1) and ethylene (Eq 1a) are suitable. The use of ethylene as the $2 \mathrm{p}$-component necessarily leaves two prochiral carbons of the cyclobutene unfunctionalized. An attractive way to circumvent this problem would be to access precursor cyclobutenes (6) with the use of alkenyl derivatives (5) in place of ethylene (Eq 1b). This further raises the intriguing possibility of preparing these chiral 3substituted cyclobutenyl derivatives via enantioselective catalysis. However, the application of reaction conditions described in Eq 1a led to complex mixtures with very little of the desired products (Eq $1 \mathrm{~b}$ ), prompting further investigations into a new strategy.
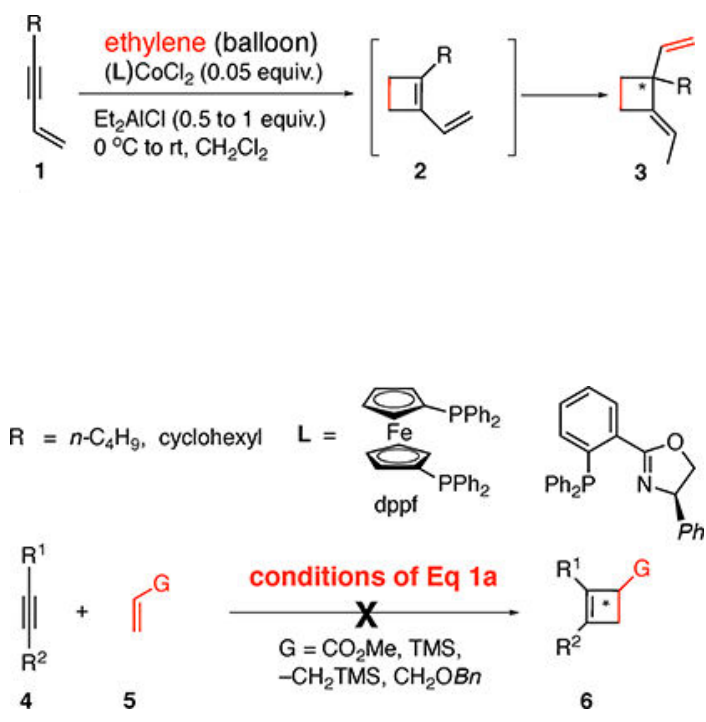

\section{A New Reaction and Optimization Studies}

Following many failed attempts to modify the reaction conditions described in Eq 1a, we wondered if the incompatibility of the Lewis bases in the substrates was the problem, and if so, could it be addressed by activation of the reagents by a cationic Co(I) species, an intermediate that was implicated in our recent 1,2-hydroboration of prochiral 1,3-dienes. ${ }^{14}$ Initial scouting experiments (Table 1) were conducted with a prototypical alkyne, 4-octyne (4a) and two acrylates, methyl acrylate (5a) and 1,1,1-trifluoroethylacrylate (5b).

Concurrently, we also studied the corresponding reaction between a more reactive enyne and methyl acrylate (Table 2). The most pertinent results from these studies are summarized in the Tables 1 and 2. Details of initial optimization of the reaction conditions, from which the results in Tables 1 and 2 are abbreviated, can be found in the Supporting Information (See Tables S1-S7, pp. S12-S20). These experiments include effects of the following parameters on the efficiency and selectivity of the reactions: (i) cobalt(II) halide ( $\mathrm{Br}$ or $\mathrm{Cl}$ ) complexes of 1,n-bis-diphenylphosphinoalkanes of varying bite angles $\left.\left[\mathrm{Ph}_{2} \mathrm{P}-\left(\mathrm{CH}_{2}\right)_{\mathrm{n}}-\mathrm{PPh}_{2}, \mathrm{n}=1-5\right)\right]$, 
including chiral variants such as chiraphos, BDPP, BDPH, DIOP, and other chelates with different backbone motifs such as dppf, biaryl, Josiphos ligands and phosphino-oxazoline ligands [see Figure 2 for structures of the ligands and Figure S1 (p. S12) in the Supporting Information, which contains a complete list of all ligands]; (ii) zinc, manganese, and, various 1,4-bis-trimethylsilyldihydropyrazines ${ }^{14,15}$ as reducing agents; (iii) activators such as $\mathrm{ZnX}_{2}$, AgOTf, $\mathrm{AgSbF}_{6}, \mathrm{InBr}_{3}$, sodium tetrakis-[3,5-(bis-trifluoromethyl)phenyl]borate (NaBARF); (iv) solvents, dichloromethane (DCM), 1,2-dichloroethane (DCE), toluene, hexanes, THF, ether, ethyl acetate or acetonitrile; (v) reaction temperature. In general, it was found that the reactions proceed best at or near room temperature in non-coordinating solvents such as DCM, DCE or toluene, with NaBARF as the most suitable activator. As expected, none of the solvents containing heteroatoms were suitable for this reaction. For enantioselective reactions, toluene was found to be a better solvent (giving 5-10\% higher enantioselectivities vis-à-vis DCM) in several instances.
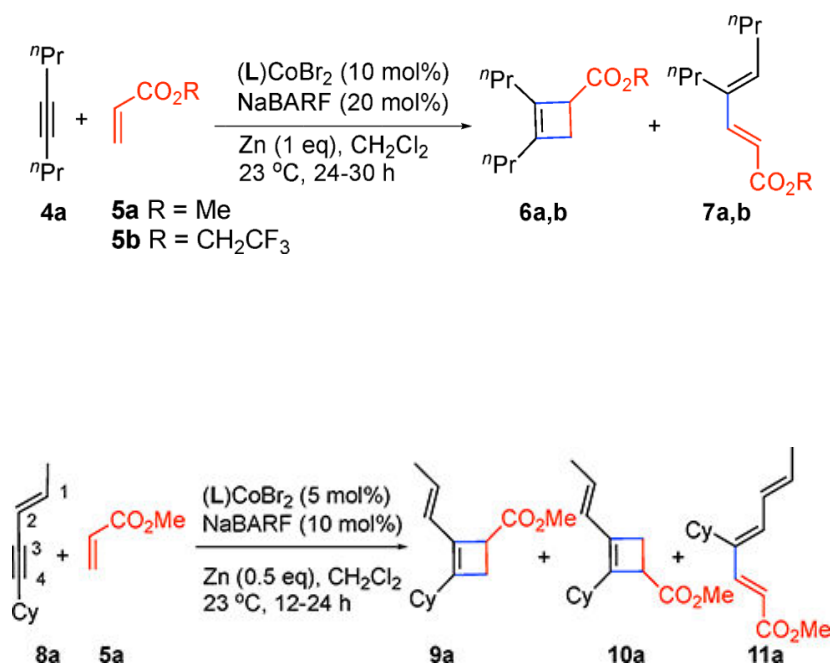

\section{[2+2]-Cycloadditions between an alkyne (4a) and alkyl acrylates (5a and $5 \mathrm{~b}$ )}

(Eq 2, Table 1)-The results for the [2+2]-cycloaddition reactions of a prototypical alkyne, 4-octyne show that for the reaction with methyl acrylate, among the 1,n-bisdiphenylphosphino-alkane $\left[\mathrm{Ph}_{2} \mathrm{P}-\left(\mathrm{CH}_{2}\right)_{n}-\mathrm{PPh}_{2}\right]$ ligands, only dppp $(\mathrm{n}=3)$ gave moderate yield of the expected cyclobutene $\mathbf{6 a}$, the others producing significant amounts of a diene byproduct 7a [Table 1, entry 1, see also: Supporting Information Table S1 (p. S13) in for a more details]. The byproduct contamination was also a major problem with other commonly used chiral bis-phosphines including (S)-BINAP (entry 3 ) and (S,S)-BDPP (entry 4).

Phosphino-oxazoline Ligands-While these studies were in progress, we were also examining the related [2+2]-cycloaddition of the acrylate 5a with the enyne 8a (see: Eq 3, Table 2), where it was found that the phosphino-oxazoline ligands, including the easily synthesized achiral ligand $\mathbf{L} \mathbf{1}$ and chiral ligand $\mathbf{L 2}$ (Figure 2), were much superior in giving the cyclobutene product $(\mathbf{9 a})$ with very high chemo- and regioselectivity. These observations, along with the highly tunable nature of the phosphino-oxazoline ligands 
prompted us to examine this ligand system for further detailed investigations. Accordingly, several of phosphino-oxazoline ligands (L1-L9) were prepared (Figure 2), and their cobalt (II) complexes studied as catalysts for the cycloaddition reaction at room temperature under conditions described in Eq 2. As can been seen in entries 7 and 8 (Table 1), with the new Cocomplexes of these ligands, the [2+2]-cycloaddition between 4-octyne and methyl acrylate proceeded to give synthetically useful yield in unprecedented levels of enantioselectivity for the cyclobutene products. Most notably, replacing the Pdiarylphosphino group in $\mathbf{L 2}$ with a dicyclohexylphosphino group (L8) produced a very active Co-catalyst that gave exclusively the cyclobutene adduct 6a in an enantiomeric excess (ee) of $90 \%$ in toluene, with none of the undesired heterodimerization product $7 a$. With yet another modification, viz., introduction of 4,5-disubstitution on the oxazoline as in the ligand $\mathbf{L} \mathbf{9}$ [readily prepared from $(1 S, 2 R)$-norephedrine], further improvements in both the reactivity and selectivity of the reaction were observed (entry 8 ). With these new ligands and use of an activated trifluoroethyl acrylate $\mathbf{5 b}$, a quantitative reaction ensued with minimal loss in selectivity (Table 1, entries 10 and 11). For the effects of a more complete set of ligands, see Supporting Information, Table S6 (p. S19).

\section{[2+2]-Cycloaddition between a 1,3-enyne (8a) and methyl acrylate (Eq 3, Table}

2)-The cycloadditions of 1,3-enynes presented further challenges, the increased reactivity of the enynes notwithstanding. In the initial investigations, we found that 1- or 2-substituted alkenyl alkynes were the best substrates for this reaction (vide infra). For example, one such substrate, 8a, with a C1-methyl substituent (Eq 3, Table 2), gave varying amounts of codimerization product (11a) along with regioisomeric mixtures, 9a and 10a, of the [2+2]cycloadducts. Most gratifyingly, these selectivity problems could be readily solved by examination of ligand effects on this reaction. See Supporting Information Tables S2-S5 (p. S14-S18) for complete optimization of reaction conditions. Initially, we found that cobaltcomplexes of achiral (entries 1-3) and chiral (entries 5-9) bisphosphine ligands were generally unsatisfactory either because of low reactivity or low selectivity. However, the phosphino-oxazoline (PHOX) ligands, including the achiral ligand L1, are excellent ligands for this transformation giving almost exclusively the expected cyclobutene product 9a. Recall that $\mathbf{L 1}$ was surprisingly ineffective in the cycloadditions of simple alkynes (e.g., Table 1, entry 5). Changing the 4-aryl substituent on the oxazoline moiety in the PHOX ligands to alkyl groups (e. g., from $\mathrm{Ph}$ in $\mathbf{L} \mathbf{2}$ to $t$-Bu in $\mathbf{L 7}$, entries 10-13) led to poorer ligands. In sharp contrast, tuning of the $P$-aryl substituents led to significant improvements in enantioselectivites (the ee's improving from $62 \%$ to $80 \%$, entries 10-12). The best results were obtained when the $P$-aryl groups were replaced by cyclohexyl groups as in $\mathbf{L 8}$, which resulted in the highest yield (98\%), regioselectivity (regioisomeric ratio, $\mathrm{rr}=>95: 5$ ), and enantioselectivity (ee $=94 \%$ ) for this substrate, especially when the reaction was carried out in toluene as the solvent (entries 15 and 16). For an ORTEP representing the solid-state structure of the pre-catalyst, $[(R)-\mathbf{L 8}] \mathrm{CoBr}_{2}$, see Figure $4(\mathrm{~A})$. The norephedrine-derived ligand $\mathbf{L 9}$, also gave high enantioselectivity (ee $=90 \%$ ), albeit with only modest regioselectivity (9a:10a $=90: 10$, entry 17$)$. With the identification of a viable protocol for the reaction and the availability of several useful ligands, the stage is now set for a broader investigation of the scope of vinyl derivatives and the alkynes. 


\section{Scope of [2+2]-Cycloadditions between Alkynes and Alkenyl Derivatives}

The optimized reaction conditions with minor modifications (Figure 3, Eq 4) were employed in the $[2+2]$-cycloaddition reactions of a wide variety of alkynes and alkenyl derivatives. The enantioselective reactions were carried out using the ligand $\mathbf{L} \mathbf{9}$ unless otherwise noted, and authentic racemic products were synthesized using the ligand rac-L8. In general, excellent yields and enantioselectivities were observed for both sets of ligands for a broad range of cyclobutenes carrying many common organic functional groups, originating either from the alkyne or the alkene. Details of the synthesis of each of the specific adducts can be found in the Supporting Information. For the sake of brevity and clarity, the products are classified according to the types of alkyne precursors (4), and, within each type, by the alkenyl partners. The simplest alkynes are the symmetric ones $\left(\mathrm{R}=n-\mathrm{Pr}, \mathrm{Ph}, \mathrm{CH}_{2} \mathrm{OTMS}\right)$ leading to products $\mathbf{6 a - 6 j}$. The alkenyl derivatives include alkyl and trifluoroethyl acrylates (6a-6d), vinyltriethoxysilane (6e), vinyltrimethylsilane $(\mathbf{6} \mathbf{f})$, vinylboronic acid pinacolate $(\mathbf{6 g}$ and $\mathbf{6 h})$, each giving excellent yields (86-97\%) and ee's (88-97\%). The trifluoroethyl acrylates were generally more reactive and the reactions proceeded at a faster rate compared to the alkyl acrylates. This permits lower temperatures for the reactions, leading to improved yields but with little change in selectivities. Among the acrylates $t$-butyl acrylate gave the product $\mathbf{6 d}$ with the highest enantioselectivity (94\%) with 4-octyne. The hydroxymethyl-bearing product $\mathbf{6 i}$,was formed in very good yield and excellent ee (95\%). Products derived from unsymmetrical alkynes bearing an aryl group and an alkyl group are represented by $\mathbf{6 k - 6 t}$. 1Phenylpropyne and 1-phenylbutyne gave high yields of the [2+2]-adducts $6 \mathbf{k}, \mathbf{6} \mathbf{l}$ and $\mathbf{6 p}$ upon reaction with the respective acrylates in excellent regioselectivity ( $\mathrm{rr}>95: 5)$ and enantioselectivity (ee >89\%), with the ester moiety placed adjacent to the aromatic substituent. Ligand $\mathbf{L 8}$ was found to be the most optimal for these aromatic substrates. The regioselectivity in the products from unsymmetrical dialkyl alkynes depends on the difference in the size of the two alkyl groups. Methyl/butyl and methyl/ $i$-propyl combination gave relatively low selectivity (62:38 and 87:13 for $\mathbf{6 m}$ and $\mathbf{6 n}$ ), even though the enantioselectivity reached $>91 \%$ ee for the major product in both cases. Significantly, the norephedrine-derived ligand $\mathbf{L 9}$ gave better regioselectivity compared to $\mathbf{L 8}$. $t$-Butylmethyl acetylene with a significant size difference between the groups underwent a highly regioselective [2+2]-cycloaddition to give the product $\mathbf{6 o}$.

Products 6q-6ai derived from functionalized, unsymmetrical alkynes, including some carrying hetero-atoms $(N, S)$ on the alkynyl carbon $(\mathbf{6 s}, \mathbf{6 a g}, \mathbf{6 a h})$, demonstrate the vast functional group compatibility of the reaction. The following additional substituents on the alkynes are tolerated: carbonyl group as in a ketone or ester (6q, $\mathbf{6 r}, \mathbf{6 t}, \mathbf{6 u}, \mathbf{6 v}$ and $\mathbf{6 a i}$ ), electron-rich or electron-poor aryl and heteroaryl groups $(6 \mathbf{6 t}, \mathbf{6 w}, \mathbf{6 x}, \mathbf{6 y}, \mathbf{6 z}, \mathbf{6 a a}, \mathbf{6 a b}, \mathbf{6 a c}$, 6ad, 6ae, 6af, 6ai), alkyl sidechains with $-\mathrm{OH}(\mathbf{6 y}),-\mathrm{Cl}(\mathbf{6 z})$, or phthalimido- (6aa) groups, cyclopropyl groups (6ab). In general, very good to excellent yields of the isolated products were obtained for a wide variety of alkenyl derivatives previously shown to work with simpler symmetric alkyne substrates. The regioselectivity observed was also high (>95:5) except for a few instances $(\mathbf{6 m}, \mathbf{6 a g}, \mathbf{6 a i})$. Where ever we have carried out the enantioselective reactions (6a-6t), the ee's are very high (86-97\%). 


\section{Scope of [2+2]-Cycloadditions between 1,3-Enynes and Alkenyl Derivatives}

1,3-Enynes as the alkyne components in the [2+2]-cycloadditions increase the versatility and applicability of this chemistry by placing yet another functionalizable carbon in the form of an alkenyl substituent on the product cyclobutene (9, Eq 5, Figure 5). The (E)-1-propenyl moiety was chosen as the optimal substituent on many of the enynes in this study for three reasons: (a) the substrates bearing this group can be easily synthesized in high yield by cross-coupling chemistry; (b) the propenyl derivative can be readily converted into a more versatile cyclobutenyl aldehyde by chemoselective ozonolysis (Figure 6, A); (c) 1,3-enynes with no alkenyl substituents require three equivalents of the alkenyl partner to promote efficient [2+2]-cycloaddition (for example, to prepare 9ac or 9ad) and to prevent a competitive co-dimerization of such enynes (example, to give 13ad, Figure 6, B) to 1,6dialkylvinylaromatic compounds. See Supporting Information Table S7 for further details.

The most general reaction conditions, applicable to the broadest spectrum of substrates, is shown in Eq 5 (Figure 5), and, the corresponding substrate scope is illustrated by the accompanying structures. The electron-rich phosphino-oxazoline ligand $\mathbf{L 8}$ appears to be the best ligand to obtain the highest regio- and enantioselectivity under the previously optimized conditions for this transformation. See also Table 2, and, a more elaborate Table S2 in the Supporting Information (p. S14) for the effect of other ligands, and Table S3 (p. S16) for the effect of solvents. Solid state structure of the most useful $\mathrm{CoBr}_{2}$-complex is shown in Figure 4 (A). The authentic racemic products were synthesized using ligand $\mathbf{L 1}$. The diverse structures of products in Figure 5 validate the broad scope of this [2+2]-cycloaddition reaction with respect to the enynes and the alkenyl derivatives. The absolute configuration of the products is based on the X-ray crystallographic structure of a 1,6-dibromo-2-naphthoate corresponding to the methyl ester 9a (Figure 4, B). Configuration of the other products are assumed by analogy.

For convenience, the products from enynes are classified into six somewhat arbitrary groups, five of them showing the variations in the starting alkenyl components - alkyl acrylates (9a-9e), hetero-functionalized alkenes (9f-9i: starting from trialkoxyvinylsilane, trialkylvinylsilane, vinylboronate and vinylsulfone), allyl derivatives (9j-9n: from allyl ethers, allyl amides, allyl pinacolboronates, allyl sulfones and allyl trialkylsilanes), vinylarenes (9o-9s), and disubstituted alkenes such as dihydrofuran $(\mathbf{9 t})$, norbornene (9u) and transanethole $(9 \mathbf{v})$. Another group of adducts $(9 \mathbf{w}-\mathbf{9 a g})$ show the variations possible in the enynes.

In most of the adducts derived from alkyl acrylates, the hetero-functionalized alkenes, and the allyl derivatives (9a-9n), the major product carries the alkenyl substituent adjacent to the 2-propenyl group of the enyne (>95:5 rr). The enantioselectivities in these instances are also excellent (generally $>90 \%$ ee), except for the adducts from allyl $N$-tosylamide $(9 \mathbf{k}, 87 \%)$ and allyl phenyl sulfone $(9 \mathrm{~m}, 55 \%)$. Cycloadditions with allyl derivatives also revealed a remarkable ligand effect. While the cycloaddition reactions carried out using the PHOX ligands ( $\mathbf{L 1}$ or $\mathbf{L 8})$ gave excellent yields of the [2+2]-cycloaddition $(\mathbf{9 j}-\mathbf{9 n})$ with outstanding regioselectivity, the (dppp)CoBr2 complex gave adducts corresponding to a formal ene reaction (Figure 6, C). ${ }^{12 a}$ See Supporting Information for other substrates showing similar 
behavior (Supporting Information Table S8, p. S21). Simple internal alkynes give only eneproducts with 1-alkenes irrespective of the ligands. ${ }^{12 \mathrm{c}}$ The vinylarenes (corresponding to the products 9o-9s) are excellent alkenes for the cycloaddition, even though the enantioselectivities seen are unacceptably low, except for the benzofuranyl compound $\mathbf{9 s}$ (ee $86 \%$ ). Compatibility of functional groups in the cyclization of enynes is similar to what was previously observed for simple alkynes (Figure 3). Thus, cyclopropyl (9w), alkyl (9x-9z), chloroalkyl (9aa), phthalimido-alkyl (9ab) or trimethylsilylvinyl (9af) groups presented no complications in the reaction. In general, very good to excellent regioselectivities ( $\mathrm{rr}>90: 10$ ) and enantioselectivities (> 89\% ee) were observed for the corresponding substrates.

As alluded to earlier, 1,3-enynes lacking substituents on the $\mathrm{C}_{\mathrm{sp} 2}$-carbons $\left(\mathrm{R}^{2}\right.$ or $\left.\mathrm{R}^{3}\right)$ gave only modest yields (e.g., 67\% for 9ac; $47 \%$ for 9 ad), even though the observed enantioselectivity was very high ( $92 \%$ ee and $94 \%$ ee respectively). A competing homodimerization of these enynes to give 1- vinyl-2,6-dialkylbenzenes (Figure 6, B) can be avoided by using excess of the alkenyl derivative (up to 3 equivalents in the case of $9 \mathbf{a c}$ and 9ad). As illustrated by the high yields and selectivities observed for examples 9ae, 9af, and 9ag (under near stoichiometric ratios of the starting materials), substitution at the internal $\mathrm{C}_{\mathrm{sp} 2}$ carbon of the enynes also promotes facile [2+2]-cycloaddition without any complication from the homodimerization of the enyne.

\section{Role of Cationic Cobalt (I) in the [2+2]-Cycloaddition Reaction and a Possible Mechanism of the Reaction}

In the initial studies we have recognized a prominent role for a cationic cobalt (I) species in these reactions. Control experiments (Eq 6 and the accompanying Table 3) confirm that no reaction ensues in the presence of isolated $\mathrm{Co}(\mathrm{I})$ complex (dppp) ${ }_{3} \mathrm{Co}_{2} \mathrm{Cl}_{2}{ }^{14}$ or a $\mathrm{Co}(\mathrm{I})$ complex formed by in situ reduction of $\mathbf{L C o B r} 2(\mathbf{L}=$ dppp or $\mathbf{L 1})$ using $\mathrm{Zn}$ as a reducing agent (See Supporting Information Table S5 for further details) in the absence of NaBARF (entry 4 and 9 versus 1 and 2). A possible unified mechanism that accounts for all products formed and the various experimental observations is shown in Figure 7. The presence of NaBARF, which presumably generates a cationic Co(I) species (15), under these reaction conditions is essential for the success of the reaction. Oxidative dimerization of the alkyne and the alkenyl reactant gives the metallacycle 17 , which could undergo reductive elimination to give the cyclic product $\mathbf{6}$ or $\mathbf{9}$. Alternately, $\beta$-hydride elimination followed by reductive elimination could give either $\mathbf{7}$ or $\mathbf{1 4}$ depending upon the substrate. Allylic derivatives with an exo-cyclic $\mathrm{CH}_{2}$ group $\left(\mathbf{1 7}, \mathrm{G}=\mathrm{CH}_{2} \mathrm{Y}\right)$ gives the formal ene-product via 19. That coordinating solvents such as THF, acetonitrile and even ethyl acetate are not suitable for the reaction also supports the intermediacy of the cationic Co(I) species $\mathbf{1 5}$ as a viable catalyst. Thus, this cycloaddition reaction joins a growing list of other alkene functionalization reactions such as dieneacrylate dimerization ${ }^{16}$ and HBPin-mediated hydroboration ${ }^{14}$ and hydrogenation ${ }^{17}$ of prochiral alkenes where cationic $\mathrm{Co}(\mathrm{I})$ have been invoked as intermediates. 


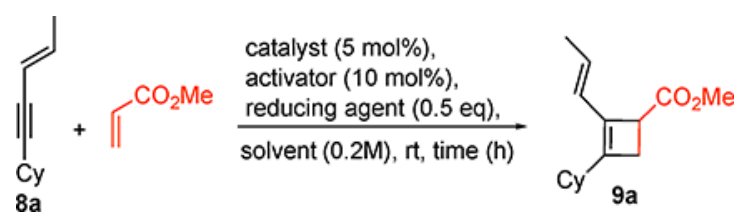

\section{CONCLUSIONS}

Cyclobutanes are important structural motifs in many biologically relevant compounds. We report a practical approach to diverse array of nearly enantiopure cyclobutenes from which these compounds can be easily accessed. Two of the most abundant organic precursors, alkynes and alkenyl derivatives are used in the key enantioselective [2+2]-cycloaddition reaction, which employs catalysts derived from readily available amino-alcohols and an earth-abundant metal, cobalt. These enantioselective cycloaddition reactions are easily scaled up to gram scale. With the diverse functional groups present in the cyclobutenes, further diastereoselective transformations are easily envisaged for synthesis of other useful intermediates including highly functionalized cyclobutanes, cyclopentanes and stereodefined 1,3-dienes. Experimental observations implicate a cationic cobalt(I)-species in the mechanism of this reaction. Such species may have broader applications for other carboncarbon and carbon-heteroatom bond-forming reactions.

\section{EXPERIMENTAL SUMMARY}

In an $\mathrm{N}_{2}$-filled glovebox, an 8-mL vial equipped with a septum screw cap was charged with a magnetic stirrer bar, $\left[\mathbf{L C o B r}_{2}\right](0.01 \mathrm{mmol}, 0.05$ equiv), activated zinc-dust ( $0.1 \mathrm{mmol}, 0.5$ equiv), NaBARF $(0.02 \mathrm{mmol}, 0.1$ equiv), and toluene $(0.20-0.25 \mathrm{M})$. The vial was capped and after stirring the mixture for 5-10 minutes, the alkyne $(0.20 \mathrm{mmol}, 1$ equiv) was added neat using microliter syringe via the septum, followed by the alkenyl derivative $(0.22-0.30$ mmol, 1.1-1.5 equiv). The resulting mixture was stirred at rt. The progress of the reaction was monitored by taking an aliquot using a glass pipette, diluting with ether and filtering through a pad of silica before analyzing via GC-FID or TLC. Upon completion of the reaction ( $4 \mathrm{~h}-24 \mathrm{~h})$, the vial was taken out of the box and quenched with ether $(5 \mathrm{~mL})$. The resulting mixture was filtered over a short pad of silica eluting with ether. Concentration on a rotary evaporator, and subsequent purification by column chromatography eluting with hexane/ethyl acetate (0 to 20\%) afforded the products. Full experimental details, spectroscopic and analytical data including chiral stationary phase chromatograms can be found in the Supporting Information under each new compound.

\section{Supplementary Material}

Refer to Web version on PubMed Central for supplementary material. 


\section{ACKNOWLEDGMENTS}

We thank Dr. J. C. Gallucci and Dr. D. Ho for the determination of the solid-state structures. Financial assistance for this research provided by the US National Institutes of Health (R01 GM108762) and the US National Science Foundation (CHE- 1900141) is gratefully acknowledged.

\section{REFERENCES}

(1). Roughley SD; Jordan AM The medicinal chemist's toolbox: an analysis of reactions used in the pursuit of drug candidates. J. Med Chem 2011, 54, 3451-3479. [PubMed: 21504168]

(2). Lovering F; Bikker J; Humblet C Escape from flatland: Increasing saturation as an approach to improving clinical success. J. Med. Chem 2009, 52, 6752-6756. [PubMed: 19827778]

(3). (a)Andrushko V; Andrushko N Stereoselective Synthesis of Drugs and Natural Products; John Wiley: Hoboken, NJ, 2013.(b)Hughes DL 'Industrial Applications of Asymmetric Synthesis' In Comprehensive Chirality; Carreira EM, Yamamoto H, Eds.; Elsevier: London, 2012; Vol. 9, pp 1-25.(c)Carey JS; Laffan D 'Active Pharmaceutical Ingredients: Structure and Impact on Synthesis' In Pharmaceutical Process Development: Current Chemical and Engineering Challenges; Blacker AJ, Williams MT, Eds.; Royal Soc Chemistry: Cambridge, 2011; Vol. 9, pp 39-65.(d)Ojima I Catalytic Asymmetric Synthesis, 3rd Edition; Wiley: Hoboken, New Jersey, 2010.(e)Carreira EM; Yamamoto H Comprehensive Chirality Elsevier: London, 2012.

(4). (a)Dembitsky VM Naturally occurring bioactive cyclobutane-containing (CBC) alkaloids in fungi, fungal endophytes, and plants. Phytomedicine 2014, 21, 1559-1581. [PubMed: 25442265] (b)Carreira EM; Fessard TC Four-Membered Ring-Containing Spirocycles: Synthetic Strategies and Opportunities. Chem. Rev 2014, 114, 8257-8322. [PubMed: 25003801] (c)Wager TT; Pettersen BA; Schmidt AW; Spracklin DK; Mente S; Butler TW; Howard H; Lettiere DJ; Rubitski DM; Wong DF; Nedza FM; Nelson FR; Rollema H; Raggon JW; Aubrecht J; Freeman JK; Marcek JM; Cianfrogna J; Cook KW; James LC; Chatman LA; Iredale PA; Banker MJ; Homiski ML; Munzner JB; Chandrasekaran RY Discovery of two clinical histamine H3 receptor antagonists: trans- $\mathrm{N}$-ethyl-3-fluoro-3-[3-fluoro-4-

(pyrrolidinylmethyl)phenyl]cyclobutanecarboxamide (PF-03654746) and trans-3-fluoro-3-[3fluoro-4-(pyrrolidin-1-ylmethyl)phenyl]- $N$-(2-methylpropyl)cyclobutanecarboxamide (PF03654764). J. Med. Chem 2011, 54, 7602-7620. [PubMed: 21928839] (d)Blakemore DC; Bryans JS; Carnell P; Carr CL; Chessum NEA; Field MJ; Kinsella N; Osborne SA; Warren AN; Williams SC Synthesis and in vivo evaluation of bicyclic gababutins. Bioorg. Med. Chem. Lett 2010, 20, 461-464. [PubMed: 20005103] (e)Slade J; Bajwa J; Liu H; Parker D; Vivelo J; Chen G-P; Calienni J; Villhauer E; Prasad K; Repic O; Blacklock TJ A concise synthesis of a novel insulin-like growth factor I receptor (IGF-IR) inhibitor. Org. Process Res. Dev 2007, 11, 825835.(f)Singh J; Bisacchi GS; Ahmad S; Godfrey JD; Kissick TP; Mitt T; Kocy O; Vu T; Papaioannou CG; Wong MK; Heikes JE; Zahler R; Mueller RH A practical asymmetric synthesis of the antiviral agent Lobucavir, BMS-180194. Org. Process Res. Dev 1998, 2, 393-399.

(5). (a)Fumagalli G; Stanton S; Bower JF Recent methodologies that exploit C-C single-bond cleavage of strained ring systems by transition metal complexes. Chem. Rev 2017, 117, 9404-9432. [PubMed: 28075115] (b)Seiser T; Saget T; Tran DN; Cramer N Cyclobutanes in catalysis. Angew. Chem. Int. Ed 2011, 50, 7740-7752.(c)Eisold M; Baumann AN; Kiefl GM; Emmerling ST; Didier D Unsaturated four-membered rings: Efficient strategies for the construction of cyclobutenes and alkylidenecyclobutanes. Chem. Eur. J 2017, 23, 1634-1644. [PubMed: 27862444] (d)Namyslo JC; Kaufmann DE The application of cyclobutane derivatives in organic synthesis. Chem. Rev 2003, 103, 1485-1538. [PubMed: 12683789] (e)Lee-Ruff E; Mladenova G Enantiomerically pure cyclobutane derivatives and their use in organic synthesis. Chem. Rev 2003, 103, 1449-1483. [PubMed: 12683788]

(6). (a)Daub ME; Jung H; Lee BJ; Won J; Baik M-H; Yoon TP Enantioselective [2+2] cycloadditions of cinnamate esters: Generalizing Lewis acid catalysis of triplet energy transfer. J. Am. Chem. Soc 2019, 141, 9543-9547. [PubMed: 31145856] (b)Cañellas S; Montgomery J; Pericàs MÀ Nickel-catalyzed reductive [2+2] cycloaddition of alkynes. J. Am. Chem. Soc 2018, 140, 1734917355. [PubMed: 30517785] (c)Wiest JM; Conner ML; Brown MK Allenoates in enantioselective [2+2] cycloadditions: From a mechanistic curiosity to a stereospecific 
transformation. J. Am. Chem. Soc 2018, 140, 15943-15949. [PubMed: 30394735] (d)Kim DK; Riedel J; Kim RS; Dong VM Cobalt catalysis for enantioselective cyclobutanone construction. J. Am. Chem. Soc 2017, 139, 10208-10211. [PubMed: 28704053] (e)Conner ML; Brown MK Synthesis of 1,3-substituted cyclobutanes by allenoate-alkene [2+2] cycloaddition. J. Org. Chem 2016, 81, 8050-8060. [PubMed: 27558964] (f)Fructos MR; Prieto A [2+2] Cycloaddition reactions promoted by group 11 metal-based catalysts. Tetrahedron 2016, 72, 355-369.(g)Poplata S; Troster A; Zou Y-Q; Bach T Recent advances in the synthesis of cyclobutanes by olefin [2+2] photocycloaddition reactions. Chem. Rev 2016, 116, 9748-9815. [PubMed: 27018601] (h)Xu Y; Conner ML; Brown MK Cyclobutane and cyclobutene synthesis: catalytic enantioselective [2+2] cycloadditions. Angew. Chem. Int. Ed 2015, 54, 11918-11928.(i)Du J; Skubi KL; Schultz DM; Yoon TP A dual-catalysis approach to enantioselective [2+2] photocycloadditions using visible light. Science 2014, 344, 392-396. [PubMed: 24763585] (j)Russell SK; Lobkovsky E; Chirik PJ Iron-catalyzed intermolecular $[2 \pi+2 \pi]$ cycloaddition. J. Am. Chem. Soc 2011, 133, 88588861. [PubMed: 21598972] (k)Frebault F; Luparia M; Oliveira MT; Goddard R; Maulide N A versatile and stereoselective synthesis of functionalized cyclobutenes. Angew. Chem. Int. Ed 2010, 49, 5672-5676.

(7). (a)Pagar VV; RajanBabu TV Tandem catalysis for asymmetric coupling of ethylene and enynes to functionalized cyclobutanes. Science 2018, 361, 68-72. [PubMed: 29976822] (b)Guisan-Ceinos M; Parra A; Martin-Heras V; Tortosa M Enantioselective synthesis of cyclobutylboronates via a copper-catalyzed desymmetrization approach. Angew. Chem. Int. Ed. Engl 2016, 55, 6969-6972. [PubMed: 27159674] (c)Wang Y-M; Bruno NC; Placeres ÁL; Zhu S; Buchwald SL

Enantioselective synthesis of carbo- and heterocycles through a CuH-catalyzed hydroalkylation approach. J. Am. Chem. Soc 2015, 137, 10524-10527. [PubMed: 26256576] (d)Secci F; Frongia A; Piras PP Stereocontrolled synthesis and functionalization of cyclobutanes and cyclobutanones. Molecules 2013, 18, 15541-15572. [PubMed: 24352013] (e)Reeves CM; Eidamshaus C; Kim J; Stoltz BM Enantioselective construction of a-quaternary cyclobutanones by catalytic asymmetric allylic alkylation. Angew. Chem. Int. Ed. Engl 2013, 52, 6718-6721. [PubMed: 23686812]

(8). Misale A; Niyomchon S; Maulide N Cyclobutenes: at a crossroad between diastereoselective syntheses of dienes and unique palladium-catalyzed asymmetric allylic substitutions. Acc. Chem. Res 2016, 49, 2444-2458. [PubMed: 27797480]

(9). (a)Beck JC; Lacker CR; Chapman LM; Reisman SE A modular approach to prepare enantioenriched cyclobutanes: synthesis of (+)-rumphellaone A. Chem. Sci 2019, 10, 2315-2319. [PubMed: 30881657] (b)Xiao K-J; Lin DW; Miura M; Zhu R-Y; Gong W; Wasa M; Yu J-Q Palladium(II)-catalyzed enantioselective $\mathrm{C}(\mathrm{sp} 3)-\mathrm{H}$ activation using a chiral hydroxamic acid ligand. J. Am. Chem. Soc 2014, 136, 8138-8142. [PubMed: 24815880]

(10). (a)Chao KC; Rayabarapu DK; Wang C-C; Cheng C-H Cross [2 + 2] Cycloaddition of bicyclic alkenes with alkynes mediated by cobalt complexes: a facile synthesis of cyclobutene derivatives. J. Org. Chem 2001, 66, 8804-8810. [PubMed: 11749610] (b)Treutwein J; Hilt G Cobaltcatalyzed [2+2] cycloaddition. Angew. Chem. Int. Ed 2008, 47, 6811-6813.(c)Fan B-M; Li X-J; Peng F-Z; Zhang H-B; Chan ASC; Shao Z-H Ligand-controlled enantioselective [2+2] cycloaddition of oxabicyclic alkenes with terminal alkynes using chiral iridium catalyst. Org. Lett 2010, 12, 304-306. [PubMed: 20025256]

(11). (a)López-Carrillo V; Echavarren AM Gold(I)-catalyzed intermolecular [2+2] cycloaddition of alkynes. J. Am. Chem. Soc 2010, 132, 9292-9294. [PubMed: 20568750] (b)Nishimura A; Ohashi M; Ogoshi S Nickel-catalyzed intermolecular [2+2] cycloaddition of conjugated enynes with alkenes. J. Am. Chem. Soc 2012, 134, 15692-15695. [PubMed: 22966854] (c)Sakai K; Kochi T; Kakiuchi F Rhodium-catalyzed intermolecular 2+2 cycloaddition of terminal alkynes with electrondeficient alkenes. Org. Lett 2013, 15, 1024-1027. [PubMed: 23398205] (d)Noucti $\mathrm{NN}$; Alexanian EJ Stereoselective nickel-catalyzed [2+2] cycloadditions of ene-allenes. Angew. Chem. Int. Ed. Engl 2015, 54, 5447-5450. [PubMed: 25758950] (e)Kumar R; Tamai E; Ohnishi A; Nishimura A; Hoshimoto Y; Ohashi M; Ogoshi S Nickel-catalyzed enantioselective synthesis of cyclobutenes via [2+2] cycloaddition of a, $\beta$-unsaturated carbonyls with 1,3-enynes. Synthesis 2016, 48, 2789-2794.(f)Shen L; Zhao K; Doitomi K; Ganguly R; Li Y-X; Shen Z-L; Hirao H; Loh T-P Lewis acid-catalyzed selective [2 + 2]-cycloaddition and dearomatizing cascade reaction of aryl alkynes with acrylates. J. Am. Chem. Soc 2017, 139, 13570-13578. [PubMed: 28880536] (g)Bai Y-B; Luo Z; Wang Y; Gao J-M; Zhang L Au-catalyzed intermolecular [2+2] 
cycloadditions between chloroalkynes and unactivated alkenes. J. Am. Chem. Soc 2018, 140, 5860-5865. [PubMed: 29618202] (h)Ding W; Yoshikai N Cobalt-catalyzed intermolecular [2+2] cycloaddition between alkynes and allenes. Angew. Chem. Int. Ed 2019, 58, 2500-2504.

(12). (a)Hilt G; Paul A; Treutwein J Cobalt catalysis at the crossroads: Cobalt-catalyzed Alder-ene reaction versus [2+2] cycloaddition. Org. Lett 2010, 12, 1536-1539. [PubMed: 20196545] (b)Nishimura A; Tamai E; Ohashi M; Ogoshi S Synthesis of cyclobutenes and allenes by cobaltcatalyzed cross-dimerization of simple alkenes with 1,3-enynes. Chem. Eur. J 2014, 20, 66136617. [PubMed: 24782325] (c)We also find that a terminal alkene such as 1-octene reacting with 4-octyne [(L9) $\mathrm{CoBr}_{2}$ (10 mol\%), Zn (1 equiv.), NaBARF (20 mol\%), toluene, rt, $24 \mathrm{~h}$ ] gives $>95 \%$ yield of the ene product $((4 E, 7 E)-5$ - propyltrideca-4,7-diene). For a related report, see: Hilt G; Treutwein J Cobalt-Catalyzed Alder-Ene Reaction. Angew. Chem. Int. Ed 2007, 46, 85008502 .

(13). (a)Qin H; Chen J; Li K; He Z; Zhou Y; Fan B Nickel-catalyzed asymmetric [2+2] cycloaddition reaction of hetero-bicyclic alkenes with internal alkynes. Chem. Asian J 2018, 13, 2431-2434. [PubMed: 29968294] (b)Schotes C; Mezzetti A Enantioselective Ficini reaction: ruthenium/ PNNP-catalyzed [2+2] cycloaddition of ynamides with cyclic enones. Angew. Chem. Int. Ed 2011, 50, 3072-3074.(c)Shibata T; Takami K; Kawachi A Rh-catalyzed enantioselective [2+2] cycloaddition of alkynyl esters and norbornene derivative. Org. Lett 2006, 8, 1343-1345. [PubMed: 16562887]

(14). Duvvuri K; Dewese KR; Parsutkar MM; Jing SM; Mehta MM; Gallucci JC; RajanBabu TV Cationic $\mathrm{Co}(\mathrm{I})$ - intermediates for hydrofunctionalization reactions: regio- and enantioselective cobalt-catalyzed 1,2-hydroboration of 1,3-dienes. J. Am. Chem. Soc 2019, 141, 7365-7375. [PubMed: 31020835]

(15). Saito T; Nishiyama H; Tanahashi H; Kawakita K; Tsurugi H; Mashima K 1,4Bis(trimethylsilyl)-1,4-diaza-2,5- cyclohexadienes as strong salt-free reductants for generating lowvalent early transition metals with electron-donating ligands. J. Am. Chem. Soc 2014, 136, 5161-5170. [PubMed: 24597916]

(16). Jing SM; Balasanthiran V; Pagar V; Gallucci JC; RajanBabu TV Catalytic enantioselective hetero-dimerization of acrylates and 1,3-dienes. J. Am. Chem. Soc 2017, 139, 18034-18043. [PubMed: 29120629]

(17). Zhong H; Friedfeld MR; Chirik PJ Syntheses and catalytic hydrogenation performance of cationic bis(phosphine) cobalt(I) diene and arene compounds. Angew. Chem. Int. Ed 2019, 58, 9194-9198. 
A. Medicinally relevant compounds containing chiral cyclobutanes

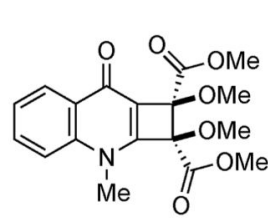

Cyclomegistine

cytotoxic

(against luekemia cell)

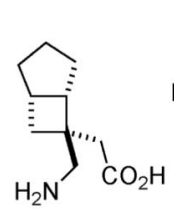

Constrained GABA analog analgesic

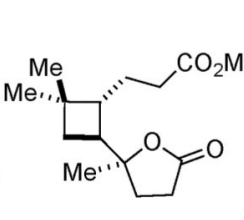

(+)-Rumphellaone A

antiproliferative

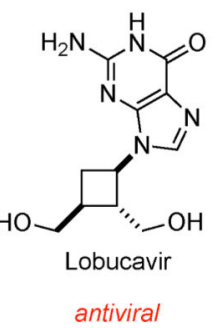

B. Chiral cyclobutenes as intermediates for other organic compounds

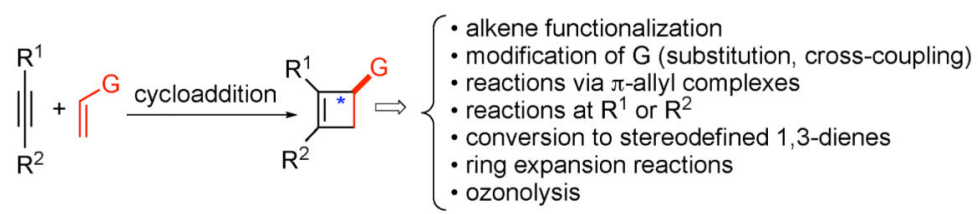

C. Cyclobutenes via enantioselective [2+2]-cycloaddition

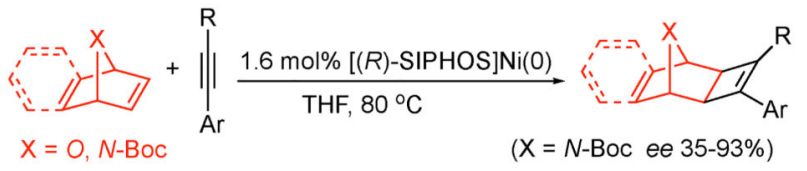

- High ee's limited to reactions of bicyclic [2.2.1]-alkenes and activated alkynes (ref 13a) - 2+2]-Cycloadditions between enynes and activated alkenes give modest ee's (ref 11e)

D. A general enantioselective synthesis of cyclobutenes (This work)

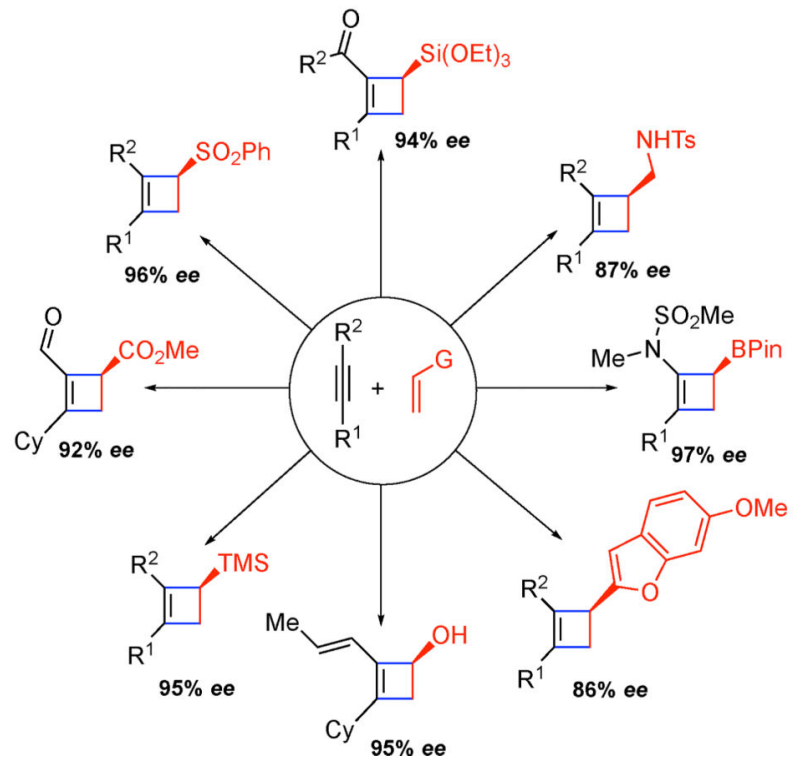

Figure 1.

A. Cyclobutane and cyclobutene motifs occur in many medicinally important small molecules and natural products. B. Cyclobutenes are excellent precursors for cyclobutanes and other useful intermediates. C. Current methods for their direct preparation via [2+2]cycloaddition are applicable only to activated alkenes and/or activated alkynes. D. This work documents a practical, catalytic enantioselective (enantiomeric excess: 86-97\%, 50 examples) approach to the most diverse set of cyclobutenes reported to-date. 

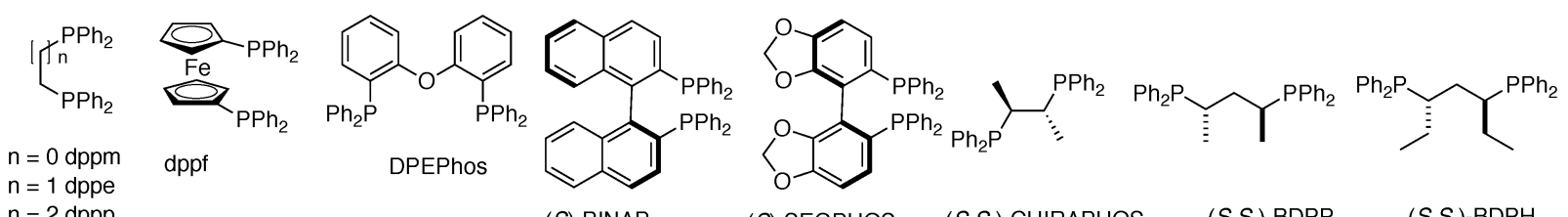

$\mathrm{n}=2 \mathrm{dppp}$ (S)-BINAP

(S)-SEGPHOS

$(S, S)$-CHIRAPHOS

$(S, S)$-BDPP

$(S, S)-\mathrm{BDPH}$

$\mathrm{n}=3 \mathrm{dppb}$
$\mathrm{n}=4 \mathrm{dpppent}$<smiles>CC1(C)OC(Cc2ccccc2)C(Cc2ccccc2)O1</smiles><smiles>[R]c1cc([R])c(P(c2cc(C)cc(C)c2)c2cc(C)cc(C)c2)c(P(c2ccccc2)c2cc([2H])cc([2H])c2)c1</smiles><smiles>Pc1ccccc1C1=NCCO1</smiles>

L1

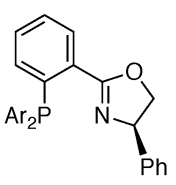

L2 $\mathrm{Ar}=\mathrm{Ph}$<smiles>PC1COC(c2ccccc2Pc2ccccc2)=N1</smiles>

L5 $\mathrm{R}=i-\mathrm{Pr}$

L3 3,5- $\left(\mathrm{CH}_{3}\right)_{2}$-phenyl L6 R $=\mathrm{CH}_{2} \mathrm{Ph}$

L4 3,5-( $\left(\mathrm{CF}_{3}\right)_{2}$-phenyl ent-L7 $\mathrm{R}=t$-Bu<smiles>c1ccc(Pc2ccccc2C2=NC(c3ccccc3)CO2)cc1</smiles>

L8

Cy = cyclohexyl

Figure 2.

Partial list of ligands examined for cobalt-catalyzed [2+2]-cycloaddition between alkynes and alkenyl derivatives 

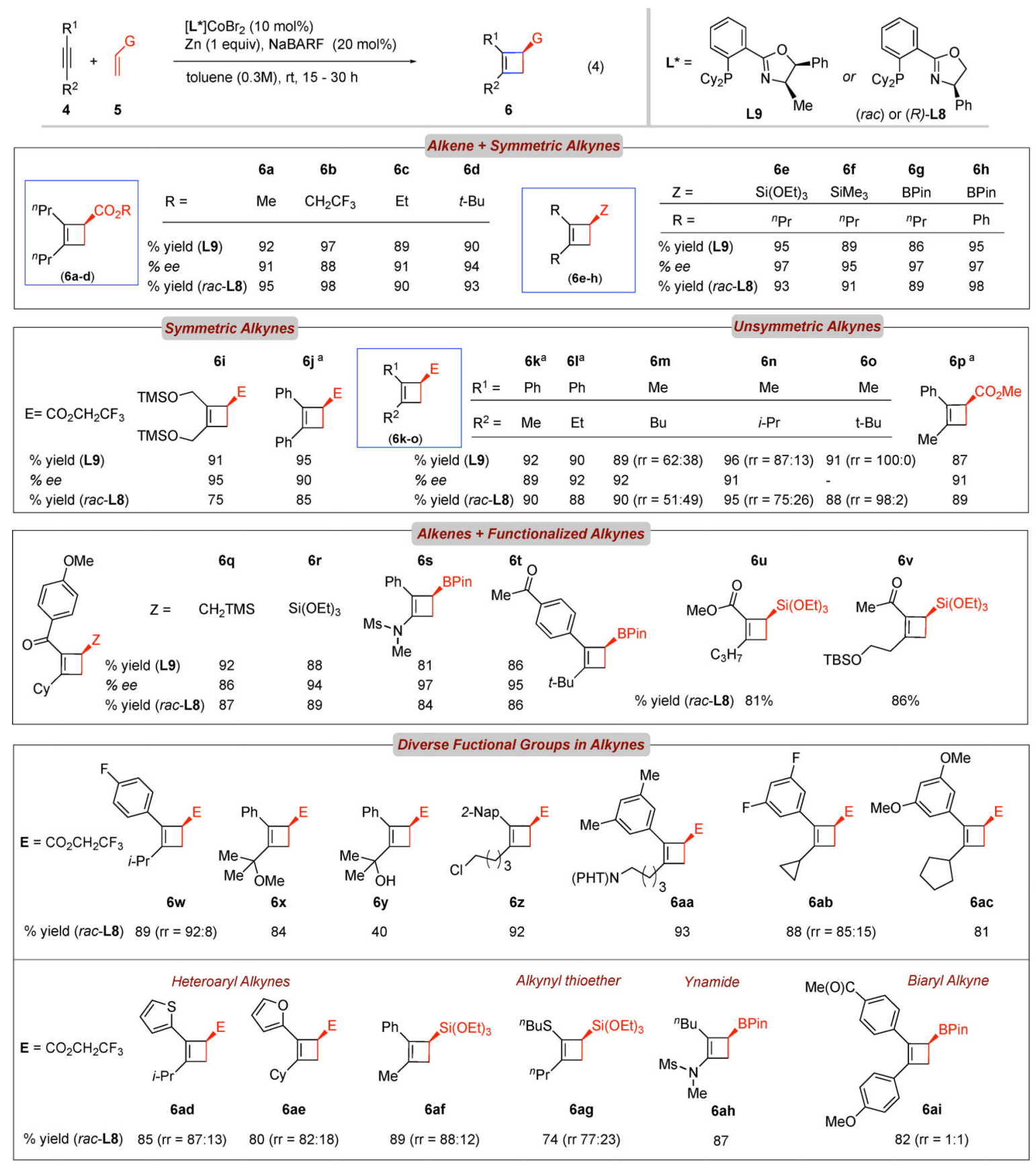

${ }^{a}$ Ligand $\mathrm{L} 8$ at $40^{\circ} \mathrm{C}$ was used. For $6 \mathrm{a}, 6 \mathbf{c}, 6 \mathrm{~d}, 6 \mathbf{v}$ to $6 \mathrm{ae}$ reaction performed at $40{ }^{\circ} \mathrm{C}$. For $6 \mathrm{e}, 6 \mathbf{f}, 6 \mathrm{~g}, 6 \mathrm{~m}$, and $6 \mathrm{n}$ reaction performed with 5 mol\% catalyst loading

Figure 3. Scope of [2+2]-Cycloaddition between Alkenyl Derivatives and Alkynes.

The versatility of the reaction is illustrated by the diverse functional group present in the two coupling partners. In unsymmetrical alkynes regioselectivities of the products (6) are >95:5 unless otherwise indicated. The structures shown are for the major regioisomers and the corresponding ee's were determined by using CSP-GC or CSP-HPLC. See the Supporting Information for further details. Yields shown are for isolated products. 


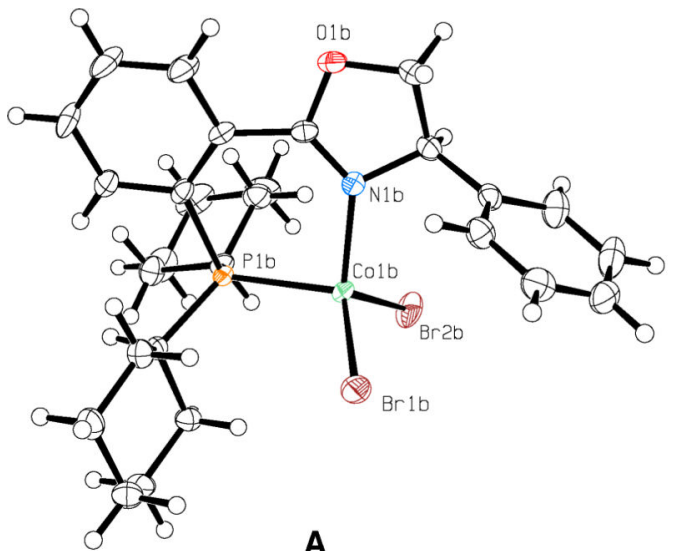

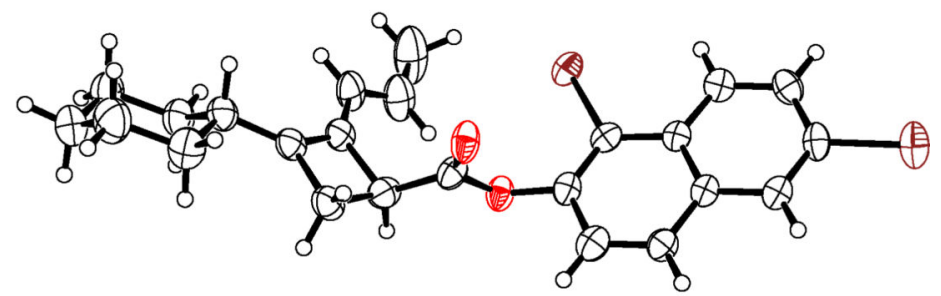

A

B

Figure 4.

A. Solid-state structure (ORTEP) of the pre-catalyst $[(R)-\mathbf{L 8}] \mathrm{CoBr} 2$ (Cambridge Crystallographic Data Centre CCDC \# 1860755). B. Absolute configuration $(S$ ) established by X-ray crystallography of a 1,6-dibromo-2-naphthoate corresponding to cyclobutene $\mathbf{9 a}$ (Cambridge Crystallographic Data Centre CCDC \# 1921037). See Supporting Information for details. 
A.

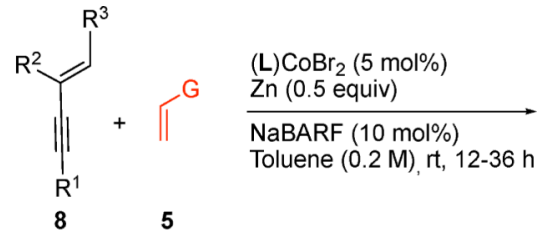

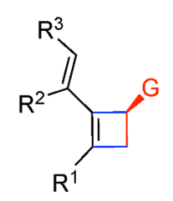

9
(5)
B.<smiles></smiles><smiles>Oc1ccccc1C1=N[C@H](P)CO1</smiles>

$(R)-$ L8

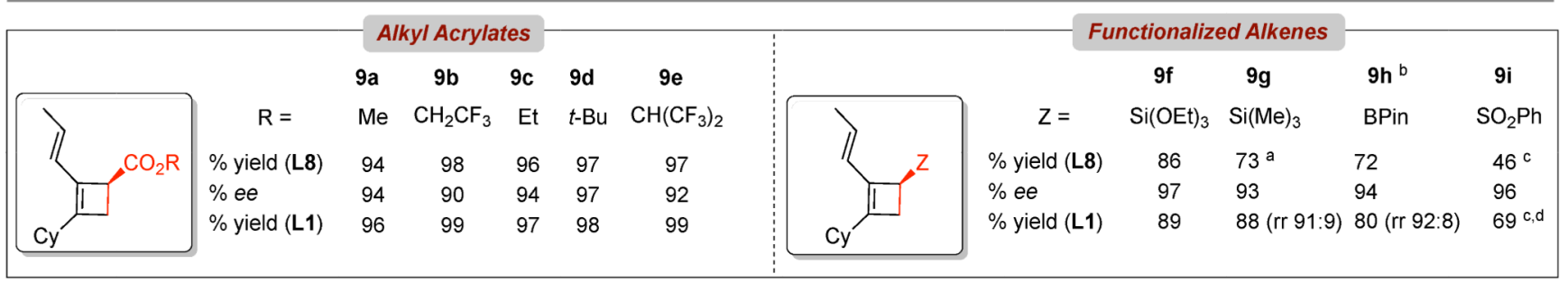

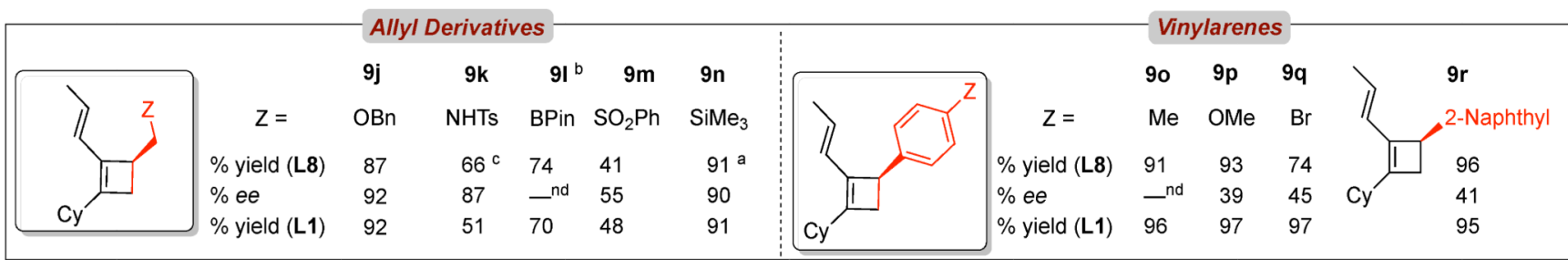

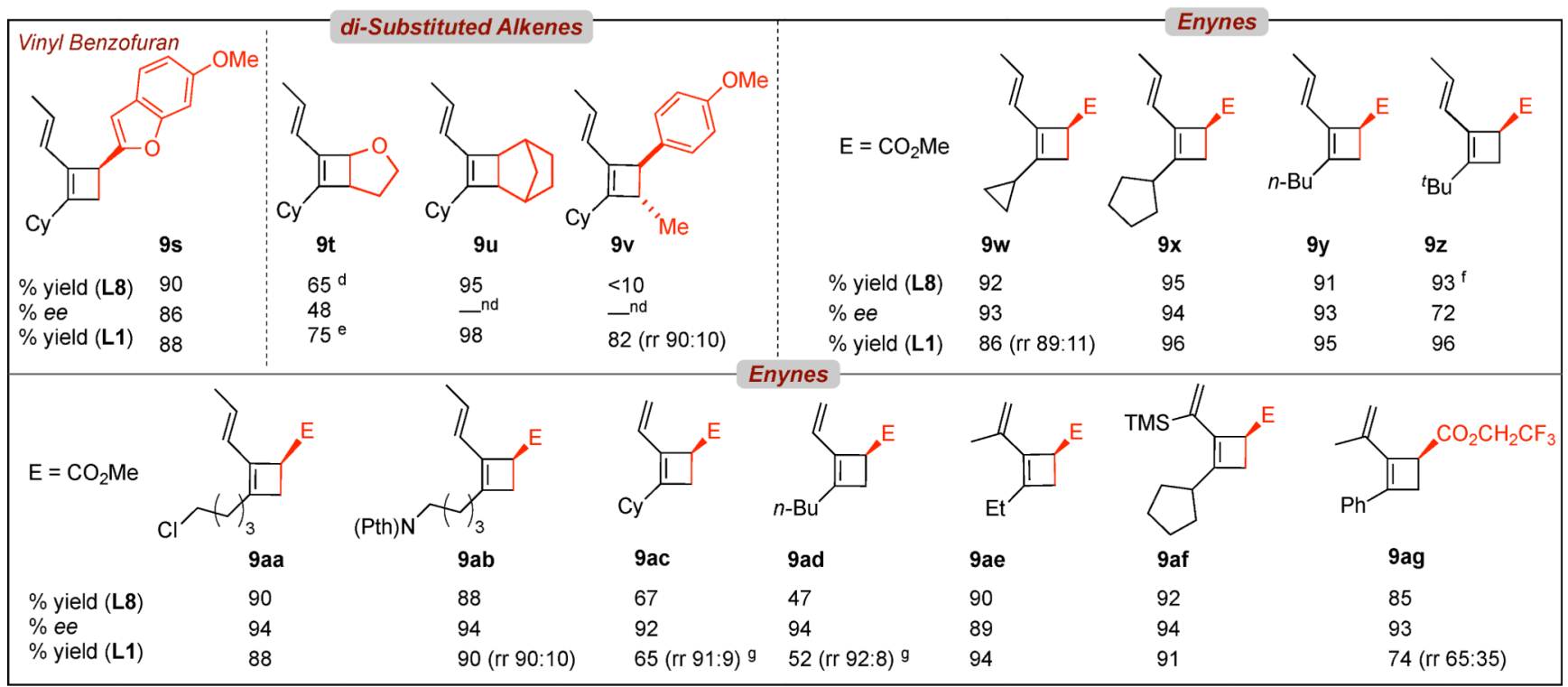

${ }^{a}$ Ligand L9 was used. ${ }^{b}$ identified as the alcohol (yields over two steps). ${ }^{c} 10$ mol\% of catalyst was used. ${ }^{d}$ DPPP was used as ligand. ${ }^{e}$ (S, S)-BDPP was used.

${ }^{f}$ Ligand L2 was used. ${ }^{9} 3$ eq methyl acrylate was used, major byproduct: 1-vinyl-2,6-dicyclohexylbenzene (from homodimerization of enyne). ${ }^{\circ}$ not determined.

Figure 5. Scope of [2+2]-Cycloaddition between Enynes and Alkenyl Derivatives.

A. Typical reaction conditions. Broad scope of the reaction is illustrated by diverse functional groups tolerated in the two coupling partners. Regioisomeric ratio of product 9 was >95:5 unless otherwise indicated. The structures shown are for the major regioisomers and the corresponding ee's were determined by using CSP-GC or CSP-HPLC. See the Supporting Information for further details. B. Most useful ligands for the $[2+2]$-additions of 1,3-enynes and alkenyl derivatives. 


\section{A. Chemoselective ozonolyis}<smiles>C/C=C/C1=C(C2CCCCC2)CC1C(=O)OC(C)(C)C</smiles>

$9 a(94 \%$ ee $)$

$12 \mathbf{a}(74 \%, 92 \%$ ee $)$

C. Remarkable ligand effect. Ene reaction vs cycloaddition

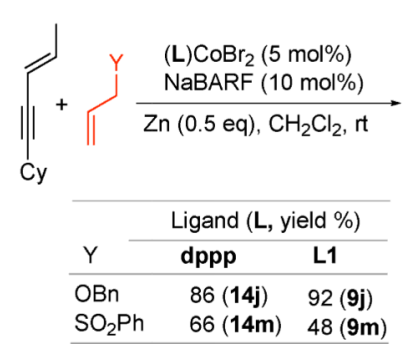

\section{B. Effect of MA concentration on homodimerization of enyne}

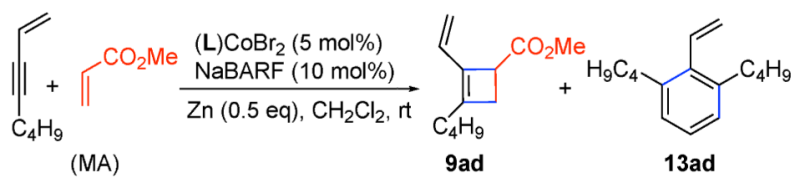

L MA (equiv.) 9ad (\%) 13ad (\%)

\begin{tabular}{llll}
\hline L1 & 2 & 38 & 60 \\
\hline L1 & 3 & 56 & 40
\end{tabular}

D. Gram-scale reaction; Diastereoselective Hydrogenation

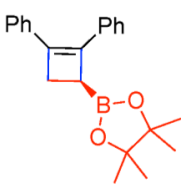

6h

$1.7 \mathrm{~g}, 92 \%$ yield, $97 \%$ ee, (from $1 \mathrm{~g}$ scale)
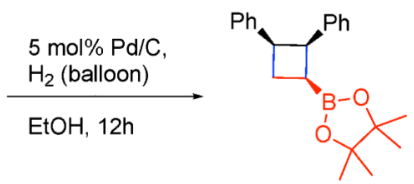

$15 \mathrm{~h}$

$96 \%$ yield, $d r>98: 2$ ee $>95 \%$

Figure 6.

A. A propenyl substituent in an enyne (thus in the cycloadduct 9a) is useful as an aldehyde surrogate. B. This group also prevents homodimerization of the enyne to a vinyl aromatic (13ad). C. Allyl derivatives give [2+2]-cycloadducts with ligand L1, but an eneproducts with dppp. D. A gram-scale reaction and a diastereoselective transformation of a cyclobutene. 


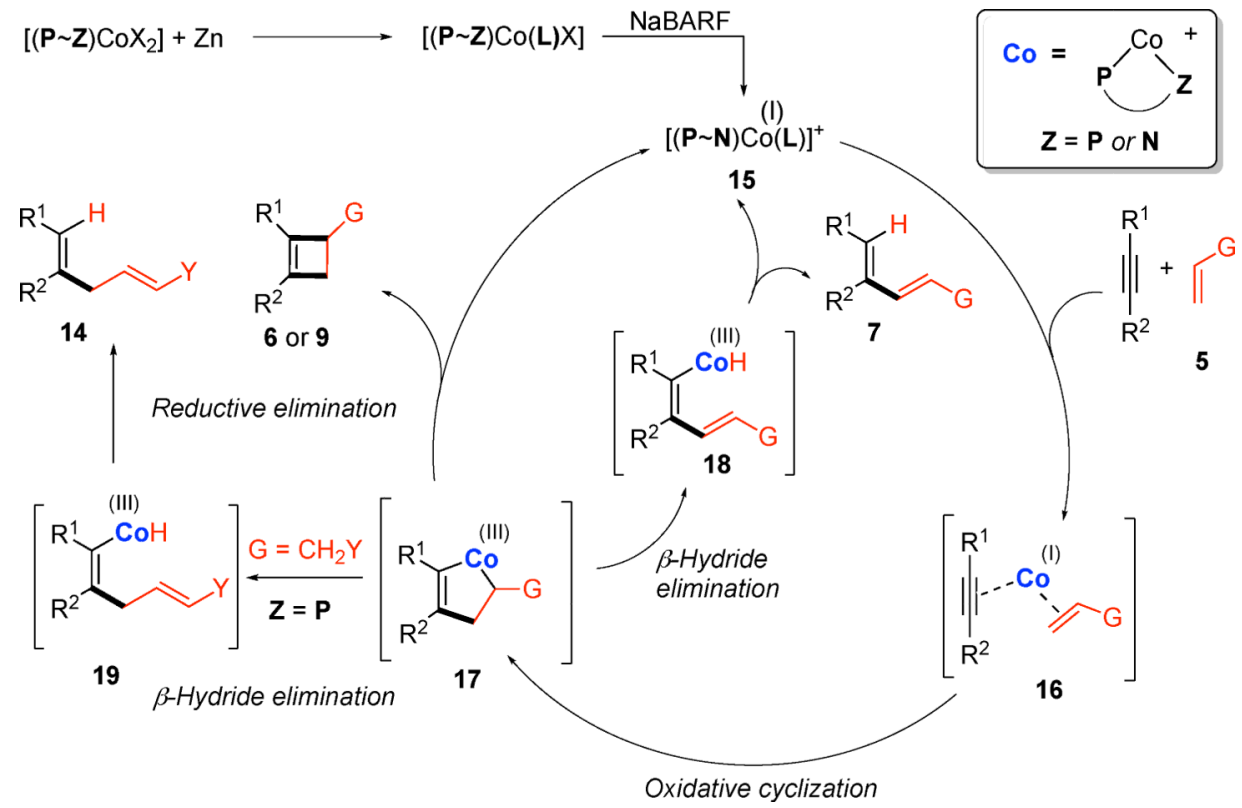

Figure 7.

A possible mechanism that accounts for the observed ligand, counter ion and solvent effects. 
Table 1.

Optimization of Co-catalyzed enantioselective $[2+2]$-cycloadditions between acrylates and an alkyne (4a) ${ }^{a}$

\begin{tabular}{|c|c|c|c|c|c|c|}
\hline & entry & ligand $^{b}$ & conv. $(\%)$ & $6 a(\%)$ & $7 \mathbf{a}(\%)$ & ee (6) \\
\hline \multirow{9}{*}{$5 a$} & 1 & dppp & 55 & 36 & 15 & 0 \\
\hline & 2 & $\mathrm{dppf}^{c}$ & 40 & 35 & 0 & 0 \\
\hline & 3 & $(S)$-BINAP & 100 & 73 & 23 & 84 \\
\hline & 4 & $(S, S)$-BDPP & 100 & 74 & 22 & 16 \\
\hline & 5 & L1 & 5 & 5 & - & 0 \\
\hline & 6 & $\mathbf{L 2}$ & 55 & 25 & 28 & - \\
\hline & 7 & $\mathbf{L 8}^{d}$ & 95 & 87 & 0 & 90 \\
\hline & 8 & L9 ${ }^{e}$ & 100 & 92 & 0 & 91 \\
\hline & & & & $6 \mathbf{b}$ & $7 b$ & \\
\hline \multirow{3}{*}{$5 b$} & 9 & $(R)$-BINAP & 100 & 47 & 42 & 90 \\
\hline & 10 & $\mathbf{L 8}^{d}$ & 100 & $>95$ & 0 & 84 \\
\hline & 11 & L9 ${ }^{d}$ & 100 & $>95$ & 0 & 88 \\
\hline
\end{tabular}

${ }^{a}$ See Eq 2 for a typical procedure.

${ }^{b}$ For structures of ligands, see Figure 2.

$c_{\text {at }} 50{ }^{\circ} \mathrm{C}$.

$d_{\text {in toluene. }}$

in toluene at $40^{\circ} \mathrm{C}$. 
Table 2.

Optimization of Co-catalyzed enantioselective [2+2]-cycloadditions between acrylate $5 \mathrm{a}$ and an enyne $8 \mathrm{a}^{a}$

\begin{tabular}{|c|c|c|c|c|c|c|}
\hline entry & ligand $^{b}$ & conv. (\%) & $9 \mathrm{a}(\%) c$ & $10 \mathrm{a}(\%){ }^{c}$ & $11 \mathrm{a}(\%) c$ & ee (9a) \\
\hline \multicolumn{7}{|c|}{ Achiral Ligands } \\
\hline 1 & dppp & 100 & 78 & 3 & 19 & 0 \\
\hline 2 & dppf & 36 & 23 & - & - & 0 \\
\hline 3 & dPEPhos & 45 & 45 & - & - & 0 \\
\hline 4 & $\mathbf{L 1}$ & 100 & 92 & 4 & - & 0 \\
\hline \multicolumn{7}{|c|}{ Chiral Ligands } \\
\hline 5 & $(S, S)$-BDPP & 97 & 80 & 3 & 13 & 52 \\
\hline 6 & $(S, S)-\mathrm{BDPH}$ & 100 & 80 & 5 & 10 & 56 \\
\hline 7 & Josiphos 1 & 50 & 40 & 40 & 2 & 64 \\
\hline 8 & Josiphos 2 & 0 & 0 & 0 & 0 & 0 \\
\hline 9 & $(S)$-BINAP & 100 & 80 & - & 16 & 18 \\
\hline 10 & L2 & 100 & 97 & 2 & 0 & 62 \\
\hline 11 & $\mathbf{L 3}$ & 100 & 93 & 2 & 0 & 54 \\
\hline 12 & $\mathbf{L 4}$ & 100 & 94 & 4 & 0 & 80 \\
\hline 13 & ent-L7 & 100 & 82 & 17 & 0 & 10 \\
\hline 14 & L8 & 100 & 95 & 3 & 0 & 82 \\
\hline $15^{d}$ & $\mathbf{L 8}$ & 100 & 92 & 4 & 0 & 94 \\
\hline $16^{d, e}$ & L8 & 100 & 98 & $<1$ & 0 & 90 \\
\hline $17^{d}$ & L9 & 100 & 90 & 10 & 0 & 90 \\
\hline
\end{tabular}

${ }^{a}$ See Eq 3 for typical procedure.

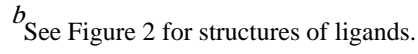

c. Yield determined by internal standard method.

$d$ Toluene used as a solvent.

$e_{\text {Trifluoroethylacrylate used instead of methyl acrylate. }}$ 


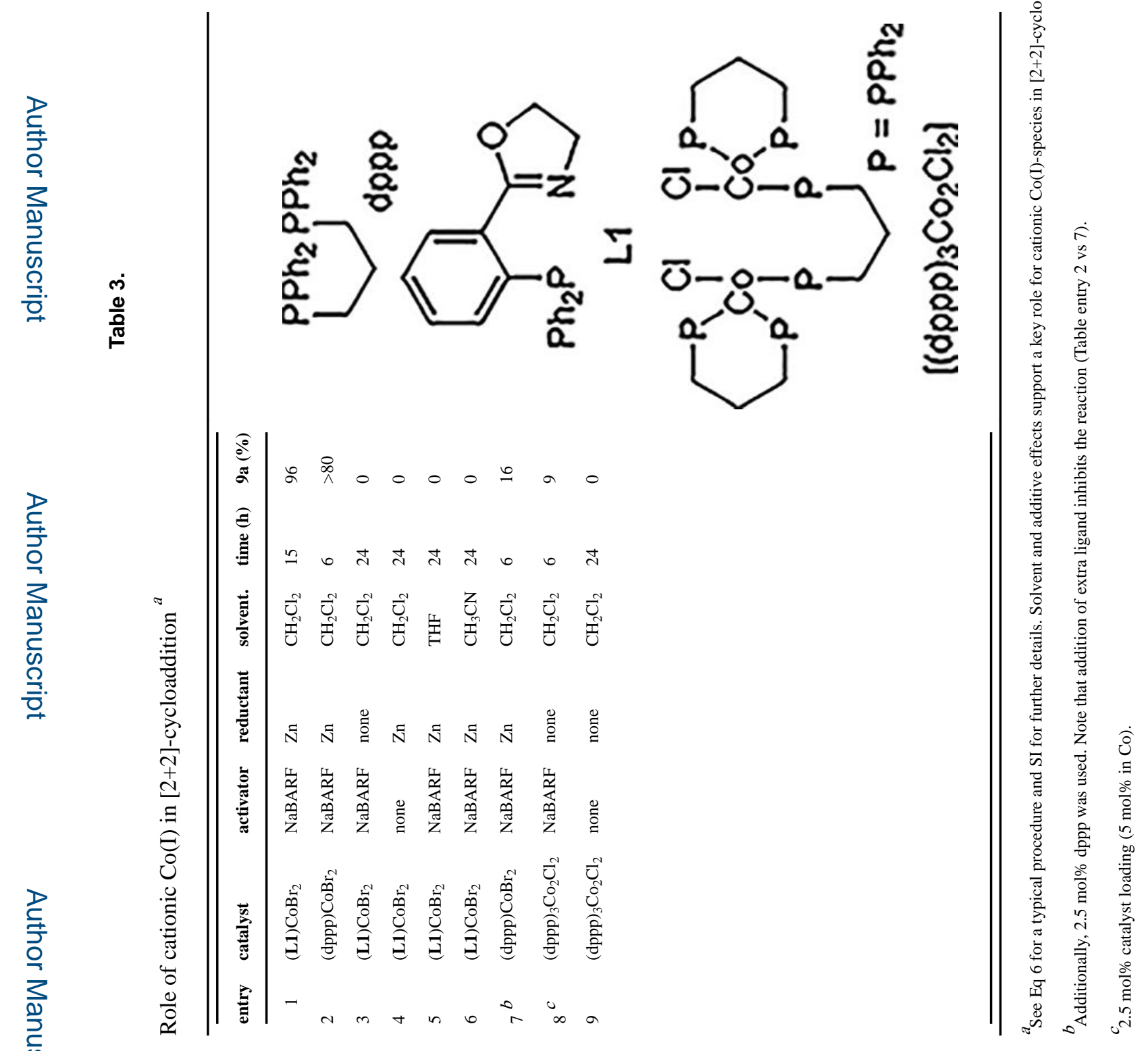

